\title{
Luchas de género en internet, una mirada desde la etnografía virtual ${ }^{*}$
}

\author{
Tania Meneses Cabrera - Carlos Andrés Martínez Garcíab - José Alfonso \\ Duartec
}

Resumen: este texto presenta los resultados de la investigación Cibercultura y Resistencia: luchas de género en internet, que tuvo por objeto de estudio las prácticas digitales como acciones contemporáneas de los movimientos sociales, en particular las prácticas de quienes trabajan por los derechos sexuales y reproductivos en América Latina y su vínculo con la Bioética social como dimensión comprensiva de las tensiones culturales. La fundamentación teórica presenta el ciberespacio como escenario sociopolítico, cultural y económico. El diseño metodológico propuso la etnografía virtual para caracterizar la emergencia de formas de ciudadanía digital a través del ciberactivismo de género. Se analizaron las prácticas de veinticinco organizaciones sociales en total, con tres perfiles específicos: feminista, nuevas masculinidades y diversidad sexual, en cinco países de Latinoamérica. Se observaron las redes sociales Facebook, Twitter y páginas web, a través de un kit de etnografía virtual diseñado por el proyecto que incluyó fichas de registro, un banco de imágenes y diverso material multimedia. Los resultados presentan el análisis de narrativas textuales y visuales de estas prácticas, tanto en su dimensión Bioética como política. Se demostró cómo el activismo digital ha facilitado la ocupación del espacio público en la sociedad de la información y genera procesos de participación política con actores y acciones emergentes por fuera de las prácticas convencionales.

Palabras clave: cibercultura; ciudadanía digital; género; movimientos sociales; Bioética

Recibido: 01/09/2020

Aceptado: 05/05/2021

Disponible en línea: 31/12/2021.

* El artículo es producto de una investigación aprobada por la Escuela de Artes y Ciencias Sociales con código PIE 24-1217, en el marco de la línea de investigación Nuevas Subjetividades del programa de Sociología. Fue desarrollada entre el 2017 y 2019. El equipo de investigadores está vinculado al Grupo Cibercultura y Territorio. Universidad Nacional Abierta y a Distancia (UNAD, Colombia).

a Doctora en Cultura y Educación Latinoamericana, magíster en Educación y socióloga, Universidad Nacional Abierta y a Distancia (UNAD), Colombia.

Correo electrónico: tania.meneses@unad.edu.co Código ORCID: https://orcid.org/0000-0001-6808-8043

b Magíster en Educación con énfasis en Educación en Línea y sociólogo, Universidad Abierta y a Distancia (UNAD), Colombia.

Correo electrónico: carlos.martínez@unad.edu.co Código ORCID: https://orcid.org/0000-0002-5307-9432

c Magíster en Comunicación y sociólogo, Universidad Abierta y a Distancia (UNAD), Colombia.

Correo electrónico: jaduarteg@unal.edu.co Código ORCID: https://orcid.org/0000-0003-1197-3871 
Cómo citar: Meneses Cabrera T, Martínez García CA, Duarte JA. Luchas de género en internet, una mirada desde la etnografía virtual. Rev. latinoam. bioet [Internet]. 31 de diciembre de 2021 [citado 31 de diciembre de 2021];21(2):57-73. Disponible en: https://revistas.unimilitar.edu.co/index.php/rlbi/article/view/5182

\section{Gender Struggles on the Internet, a Look from Virtual Ethnography}

Summary: This text presents the results of a research on Cyberculture and Resistance: gender struggles on the internet, which aimed to study digital practices as contemporary actions of social movements, particularly the practices of those who work for sexual and reproductive rights in Latin America and its link with social bioethics as a comprehensive dimension of cultural tensions. The theoretical foundation presents cyberspace as a socio-political, cultural, and economic scenario. The methodological design proposed virtual ethnography to characterize the emergence of digital citizenship forms through gender cyberactivism. Practices of twenty-five social organizations in total were analyzed, with three specific profiles: feminist, new masculinities, and sexual diversity, in five Latin American countries. Facebook, Twitter, and webpages are observed through a virtual ethnography kit designed by the project, which included registration sheets, an image bank and different multimedia material. The results present the analysis of textual and visual narratives of these practices, both in their bioethical and political dimension. It demonstrated how digital activism facilitated the occupation of public space in the information society and the generation of processes for political participation with emerging stakeholders and actions outside conventional practices.

Keywords: cyberculture; digital citizenship; gender; social movements; bioethics

\section{Lutas de gênero na internet, uma perspectiva a partir da etnografia virtual}

Resumo: Este texto apresenta os resultados da pesquisa Cibercultura e Resistência: Lutas de Gênero na Internet, que teve como objetivo estudar as práticas digitais como ações contemporâneas dos movimentos sociais, em particular as práticas daqueles que trabalham pelos direitos sexuais e reprodutivos na América Latina e sua ligação com a Bioética social como dimensão abrangente das tensões culturais. Os fundamentos teóricos apresentam o ciberespaço como um cenário sociopolítico, cultural e econômico. O desenho metodológico propôs a etnografia virtual para caracterizar o surgimento de formas de cidadania digital por meio do ciberativismo de gênero. Analisamos as práticas de vinte e cinco organizações sociais no total, com três perfis específicos: feminista, novas masculinidades e diversidade sexual, em cinco países latino-americanos. As redes sociais Facebook, Twitter e sites foram observados por meio de um kit de etnografia virtual desenhado pelo projeto e que incluía fichas de registro, um banco de imagens e vários materiais multimídia. Os resultados apresentam a análise das narrativas textuais e visuais dessas práticas, tanto em suas dimensões Bioéticas quanto políticas. Foi demonstrado como o ativismo digital tem facilitado a ocupação do espaço público na sociedade da informação e gera processos de participação política com atores e ações emergentes que se encontram fora das práticas convencionais.

Palavras-chave: cibercultura; cidadania digital; gênero; movimentos sociais; Bioética 


\section{Introducción}

La Bioética, en la construcción de su campo de estudio, ha reconocido la necesidad de ir más allá de los vínculos con las ciencias médicas y biológicas, al comprender que los cambios en las dinámicas sociales contemporáneas significan un transitar hacia una Bioética social e, incluso desde una perspectiva crítica, hacia una Bioética de género, entendida como una acepción nueva en las discusiones académicas, según lo plantea Cuevas-Silva et al. (1), y que requiere un diálogo interdisciplinar para abordar problemas emergentes que demandan un marco axiológico de la Bioética.

Es el caso de la temática abordada por la investigación Cibercultura y resistencia: luchas de género en internet, de la cual se presentan los resultados en este artículo. Se indaga sobre qué tipo de luchas y resistencias relacionadas con el género emergen en internet y cómo se tensiona la cultura a partir de estas mediaciones comunicativas. Responder a esta pregunta requiere profundizar en un escenario multisituado que combina las acciones en el mundo físico con las del mundo digital, lo que formula unas prácticas comunicativas que construyen subjetividades y acciones colectivas, en este caso, a través de las redes sociales.

En la investigación se realizó una contextualización que describe las condiciones políticas y socioculturales que promueven el uso de las tecnologías de la información y la comunicación (2). A partir de ello se identifica un uso masivo caracterizado por la apropiación de las tecnologías en los movimientos sociales con enfoque de género, así como las implicaciones de estas lógicas para los sujetos en la construcción de ciudadanías digitales a partir del activismo digital (3).

Analizar los movimientos sociales desde la perspectiva de género implicó revisar las relaciones género-tecnología. Butler (4), que desde su teoría de la dimensión performativa del género nos acerca a la diferenciación entre sexo (macho/hembra) y género (hombre/mujer), propone la idea de que sexo es a la naturaleza lo que género es a cultura, y plantea que tanto uno como otro son constructos socioculturales. Desde este enfoque, en las tensiones dadas por los procesos de apropiación tecnológica, vale la pena reflexionar acerca de una posible alteración y desplazamiento de las nociones de género naturalizadas en que se basa la hegemonía masculina y el poder heterosexista. Se desesencializa, para desestabilizar la categoría mujer o mujeres, hombre u hombres, cuestión que motiva a comprender un significante político, ahora ampliado bajo la denominación de género, pero no modificado en tanto significante.

Con esta claridad, el juego de significado y significante se tensiona en el escenario de la comunicación contemporánea y se usa internet como un elemento estratégico de primer orden para las causas de género, en función de objetivos concretos. Por un lado, se rompen las hegemonías con los medios de comunicación convencionales que históricamente han posicionado la heteronormatividad y se amplifica la capacidad de distribución de contenidos, habitualmente ignorados en las agendas mediáticas (5), al tiempo que se fortalece una identidad de luchas de género que va más allá de las reivindicaciones por los derechos de las mujeres.

En este contexto, la dimensión Bioética se plantea en el sentido de valorar los nuevos enfoques de la condición humana a partir de la influencia de la tecnología (6) y, en este sentido, el ciberactivismo como práctica propia de la democracia contemporánea, ya que toda reivindicación de derechos sexuales y reproductivos genera, en prospectiva, demandas al sistema de ciencia y tecnología, sobre lo que está permitido o no (7). Por otro lado, se encuentra la cuestión de género propiamente dicha, bajo la cual se tensiona la cultura de la norma y lo normal, desde la cual se construyeron las relaciones de poder que hoy nos gobiernan. Velayos-Castelo(8) reconoce en los cuerpos un campo de reflexión tanto de la Bioética como de los estudios de género. Temas como la violencia contra la mujer, el aborto y el feminicidio (9) han sido visibilizados como objetos de estudio y problemas pertinentes en la discusión Bioética y biopolítica actual.

\section{Metodología}

Desde la perspectiva anterior, la investigación propuso cuatro categorías de estudio: una primera, denominada pedagógica, que se concibe como 
la búsqueda desde distintas formas de enseñanza y aprendizaje, como el poder comunicar y expresar el acceso a un conocimiento sobre asuntos de género que no siempre es facilitado ni accesible desde canales educativos tradicionales a grandes grupos poblacionales. Esta categoría ha sido trabajada desde la comunicación por Reig (10) cuando plantea la necesidad de transitar de las tecnologías de la información y la comunicación a las tecnologías del aprendizaje, la colaboración, el empoderamiento y la participación.

Una segunda categoría es la denuncia, desde la cual se entrevé un accionar que permite la visibilización de las expresiones colectivas que, de manera pública, revelan hechos y acontecimientos que afectan a los colectivos de género en América Latina. Una tercera es el empoderamiento, contemplada desde la transformación, resignificación de acciones que promueven la superación de obstáculos históricamente enmarcados en las luchas de género y que encuentran en los medios digitales espacios alternativos. Por último, una cuarta categoría, denominada movilización, se observa desde la convocatoria a manifestaciones particulares de los debates propios de género, lo que implica no solamente aquellas que hacen eco desde los medios digitales, sino aquellas que trascienden o que se originan en espacios públicos físicos. Como lo propone Manzano-Zambruno (11), estas acciones reconfiguran las nociones de movimientos sociales en relación con el uso de las redes sociales, la capacidad de movilización y el empoderamiento, a partir del estudio realizado al movimiento me too, que tiene varias cosas en común con la investigación aquí expuesta.

Estas categorías fueron identificadas a partir de la aplicación de un primer instrumento de recolección de información, tipo guía de observación no participante, realizado en las páginas web, las cuentas de Facebook y Twitter de los colectivos y de las organizaciones sociales participantes, a través de las cuales se reconocieron las principales tendencias en el tema de la publicación. Estos temas se volvieron referentes para la construcción de las categorías de análisis que permiten la lectura de este hecho social descrito por la investigación.

En cuanto a las prácticas metodológicas, es preciso aclarar que para el caso de las investigaciones sobre internet y en internet, las ciencias de la comunicación y las ciencias sociales han advertido la necesidad de enfoques y herramientas que permitan abordar el ciberespacio como espacio cultural productor de subjetividad y objeto de estudio de alto interés, no solamente para las ciencias de la tecnología, sino también para las humanidades. En este camino han identificado la ausencia de protocolos de investigación en internet, frente a lo cual han avanzado, de manera tímida, pero creativa, en la construcción de opciones, tal como lo plantea Arriazu-Muñoz (12). Para el caso de esta investigación, el diseño metodológico estuvo centrado en el análisis etnográfico virtual, o netnografía, como también se le denomina de acuerdo con Turpo-Gerbera (13), en el sentido de que propone unas prácticas metodológicas muy cercanas a la labor artesanal del etnógrafo para comprender las manifestaciones e interacciones que se están dando específicamente en las redes sociales.

Para la investigación se realizó una ruta cualitativa y signada por la etnografía en espacios virtuales. Se tomó distancia de los análisis cuantitativos que se centran en el número de seguidores dependiendo del tipo de medio social que se esté observando, el número de publicaciones y el número de interacciones, siguiendo las apuestas de Boellstorff et al. (14). La etnografía tiene una larga tradición de aplicación antropológica reconocida como el trabajo de campo, pero la etnografía no se trata solamente de una técnica de recolección de información que busca describir de forma detallada el objeto de la investigación, también es un proceso por medio del cual quien hace etnografía "intenta aprender o comprender algún grupo humano" (15, p72).

En este caso, comprender las luchas de género a través de internet como mediadora comunicativa requería la apropiación por parte de los y las investigadoras, tanto de los principios metodológicos 
como de su necesaria reconfiguración. Si antes la etnografía era un privilegio antropológico en las selvas y el campo, ahora incursiona en los espacios digitales de internet en donde los procesos de interacción mediada por las tecnologías han permitido la construcción de sentidos e identidades. Este enfoque metodológico es una indagación por la cultura y por las diversas maneras en la constitución de subjetividades (16).

La necesidad de la antropología, la sociología y la psicología de conocer la forma en que el uso cotidiano de internet y sus herramientas tecnológicas están aportando a la construcción y reconfiguración de intereses e identidades requiere de la redefinición y adaptación de las estrategias metodológicas tradicionales a estos nuevos lugares de la interacción humana. Por esto, ahora se habla de la etnografía virtual como una metodología de recolección y análisis de la información en entornos digitales. Este interés también reside en poder mostrar la preocupación por parte de los investigadores de nombrar el tipo de trabajo que realizan en los mundos virtuales para el estudio de las prácticas socioculturales que allí se observan (17).

Esta reubicación de escenarios de interacción, lugares de observación y descripción de las acciones determina la forma en que el sujeto se presenta y representa sus intereses, deseos y sentires, mediado por una narrativa audiovisual y unos formatos compuestos específicamente para el medio en internet en el cual es puesto en escena. Entonces, mientras en el caso del mundo "real" lo que hacemos es rastrear sus pasos e interacciones en escenarios específicos, en el caso de lo digital lo que hacemos es seguir perfiles y observar sus publicaciones e interacciones en medios sociales (18). Este planteamiento se organiza con los componentes básicos de una situación social: actores, comportamientos, espacio y tiempo, que es fundamental para el proceso de observación.

En la etnografía se trata de comprender en profundidad la situación social identificando y caracterizando a los actores por medio de una descripción detallada. Los comportamientos o acciones en espacios y tiempos específicos, como lo expone la Imagen 1, evidencian esta relación.

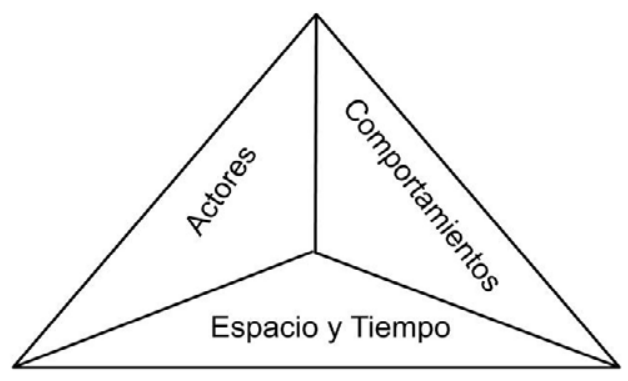

Imagen 1. Componentes básicos de una situación social

Tomado de Sparadley (1980) en Bonilla-Castro y Rodríguez (19, p230).

\section{Muestra}

Se inició consolidando los instrumentos de recolección de información que indagaban inicialmente por la forma de uso de las herramientas Twitter, Facebook y páginas web de las organizaciones sociales con enfoque de género, identificadas en ese momento a través de las bases de datos que desarrollan trabajo sobre la temática específica de género en América Latina, LANIC (20). Las organizaciones se filtraron y se seleccionaron bajo el criterio de que debían tener una página web y hacer presencia en redes sociales como Twitter y Facebook. Otro de los criterios establecidos fue que respondieran al enfoque planteado en el proyecto: ciudadanía digital y su tensión con el concepto de género.

Finalmente, se identificaron las siguientes organizaciones con presencia en internet como la muestra con la cual se realizaría la etnografía virtual:

- Mujeres En Red. El Periódico Feminista (América Latina).

- Instituto Nacional de las Mujeres, Inamu (Costa Rica).

- Corporación Miles (Chile).

- Escuela de Defensa Personal de Mujeres, Comando Colibrí (México). 
- Uso Estratégico de Internet para el Desarrollo, Colnodo (Colombia).

- Colectivo Feminista, Luchadoras (México).

- Fundación Mujer y Futuro (Colombia).

- Fondo Lunaria (Colombia).

- Asociación de Mujeres Trabajadoras del Sexo, Colectivo Flor de Azalea (Ecuador).

- La Casa del Encuentro (Argentina).

- Red Iberoamericana de Educación LGBTI (Uruguay).

- Casa de la Mujer (Colombia).

- Fundación Camino Claro (Colombia).

- Medio de Comunicación Alternativo, El Churo (América Latina).

- Colectivo de Mujeres Feministas, Conspirando (Chile).

- Fundación Instituto de la Mujer (Chile).

- Red Nacional de Mujeres (Colombia).

- Revista Digital Pillku (América Latina).

- $100 \%$ Diversidad y Derechos (Argentina).

- Colombia Diversa (Colombia).

- Fundación Igualdad LGBT (Bolivia).

- Salud, Sexualidad y Solidaridad, Promsex (Perú).

- Red Argentina de Masculinidades por la Equidad (Argentina).

- Red Iberoamericana y Africana de Masculinidades, Riam (Cuba).

En cuanto a la metodología, aparece también la problematización desde la Bioética caracterizada por la concepción de sus propios problemas, de la realidad de la que se ocupa, como objeto de dominación más que de conocimiento, como lo plantea Albert (21). La metodología nos cuestiona por la selección de la muestra y las decisiones que se tomaron a la hora de realizar el trabajo de campo, por ejemplo, no se incluyó ningún colectivo ni organización en contra del aborto o la homosexualidad, temas que tienen más prácticas activistas en redes sociales.

\section{Recolección de información}

La etnografía virtual, como indican Bárcenas-Barajas y Preza-Carreño (22), permite utilizar diferentes herramientas de recolección y registro de datos producidos por los participantes de la investigación debido a que implican el registro de situaciones de su vida cotidiana, en este caso, de su rastro en el ciberespacio.

Para la recolección de la información de esta investigación se diseñaron tres instrumentos de observación por cada medio observado: la página web de cada organización y cada uno de sus perfiles en Twitter y Facebook. Inicialmente se planteó recopilar información sobre los usos y prácticas de estas plataformas y para ello se establecieron unos primeros criterios que tenían que ver con la forma en que cada una de las organizaciones seleccionadas para este proceso de observación implementa su comunicación e interactúa usando estos medios. El tipo de contenido que se comparte se seleccionó de la siguiente manera:

Referencia a

- mención de usuarios, uso de etiquetas,

- tema de la publicación,

- estética de la publicación, en el caso específico de las imágenes.

\section{La observación}

Según Moncayo (23), la etnografía en internet permite aplicar las técnicas tradicionales como, por ejemplo, hacer observaciones de páginas web y apoyarse, además, en el análisis de contenido. Se puede, también, observar e interpretar el texto en los distintos contextos de las TIC que propician la interacción, como es el caso de las redes sociales, en las cuales el material de análisis lo conforman las opiniones o argumentos de los usuarios.

Para el caso de esta investigación, se definió como ventana de observación desde el mes de junio de 2018 hasta junio de 2019. Luego de desarrollar algunas observaciones, se determinó que esta 
ventana de observación operaría para las redes sociales, siempre buscando aquellos contenidos que las organizaciones sociales observadas compartían en Facebook y Twitter, contenidos relacionados con ciudadanías digitales y género. En cuanto a las páginas, se identificó que su contenido era más estático que el de las redes sociales y por ello se estableció que se solo se realizaría una observación de entrada y una de salida para describirlas dentro la ventana temporal de observación.

El registro y la sistematización del proceso son imprescindibles en el desarrollo de la investigación y se inicia con el análisis de los registros que se convierten en relatos reflexionados, interpretados y argumentados, como lo indican García-Gutiérrez et al. (7). Para el caso de la sistematización de esta observación, esta se realiza en la plataforma Google Drive por medio de formularios en los que se hace una identificación de la organización con su nombre y se realiza una caracterización del uso de las redes sociales, la página web y el contenido que se comparte relacionado con las categorías que se definieron inicialmente. Hacer la caracterización usando esta herramienta nos arroja bases de datos consolidadas y nos permite organizar mejor el proceso de análisis e interpretación de los datos.

\section{Análisis e interpretación}

El proceso de análisis e interpretación de los datos se basa en la teoría fundamentada o grounded theory (24), la cual permite partir de la búsqueda de gran variedad de datos, principalmente cualitativos, antes de tener una respuesta teórica. Es en la sistematización, análisis e interpretación de estos datos en la que se relaciona y construye la teoría relevante para solucionar el problema, se privilegia el análisis o la interpretación de los datos recolectados para la generación de la teoría. En esta medida, la investigación no requiere de un marco teórico previo que delimita la búsqueda e interpretación de la información, al contrario, se cuenta con algunas categorías de observación y análisis y, al momento de interpretar los datos, se pueden identificar nuevas categorías que ayuden a comprender la realidad observada (25).
Analizar la información "(...) sigue procedimientos estándar para observar, medir y comunicarse con los demás sobre la naturaleza del mundo exterior, la realidad de los mundos cotidianos tal como los experimentamos (...)" $(26$, p16). En cambio, la interpretación “(...) invita a examinar, a ponderar los datos en términos de lo que significan para las personas(...)" (26, p16) y, en cuanto a la recurrencia, surgen de la lectura y del análisis de los datos que presentan repeticiones que permiten identificar unas temáticas que, con cierta frecuencia, se pueden convertir en categorías y que, para nuestro caso, se identificaron como las categorías pedagógica, movilización, empoderamiento y denuncia.

Estas categorías, leídas desde la Bioética social, provocan reflexiones articuladas de manera directa a la categoría género, muestran sus vínculos con la corporalidad y las limitaciones normativas que cada sociedad ha impuesto como norma cultural o como norma legal, pero, además, también la Bioética como puente de comunicación, inicialmente entre los discursos de las ciencias y las humanidades, debe dar cuenta del uso de las tecnologías de la comunicación que tratan estos temas. Como lo expresa Pérez (27), ello requiere de un diálogo social que promueva un consenso acerca de la inflexión civilizatoria y la gobernabilidad global.

\section{Resultados y discusión}

Los asuntos relacionados con el género han estado bastante invisibles a la Bioética, como lo afirma De los Ríos (28), cuando explora cómo en la historia de la Bioética liberal se prestaba poca atención a la dimensión social y política, y que fue solo hasta los años 1970 que se empezó a trabajar en una concepción alternativa de la moralidad. Al respecto, indica: “(...) no obstante, la ética feminista apenas fue considerada por la ética en aquel momento. En los ochenta, al tiempo que las dificultades culturales empezaban a ser relevantes en la esfera pública, la perspectiva de género reclamó una visión más amplia del discurso bioético" (28, p256).

Es justamente esa dimensión sociopolítica que involucra el derecho de los cuerpos, el que interpelan los activismos sobre los que aquí indagamos. 
En este sentido, incorporar la dimensión Bioética en esta comprensión es proponer un diálogo con el género que, como lo plantea Estrada-Montoya (29), promueva el respeto por la autonomía de hombres y mujeres, sin importar su orientación sexual ni su identidad de género, y priorizando los valores de libertad y justicia. Es claro, entonces, que son las dinámicas sociales emergentes aquellas que demandan de la Bioética una postura frente a las tensiones sociales a que dan lugar la reivindicación de sus derechos. En este sentido, la comunicación se vuelve una herramienta muy importante para promover la transformación a los sistemas de creencias bajo los que se ha constituido la heteronormatividad como relación de poder hegemónica y la violencia de género como práctica normalizada y sistemática de nuestra cultura.

Los colectivos, organizaciones y movimientos sociales siempre han tenido una estrategia de información y de divulgación intrínseca a su trabajo, han usado los medios a su alcance y según el momento histórico que viven. En el caso de las reivindicaciones por los derechos de género, han hecho un recorrido icónico particular a sus demandas. Otrora fue la radio, los boletines y los periódicos clandestinos los que se usaron para informar, educar, convocar, empoderar y movilizar, teniendo en cuenta la carga de censura que en los países de América Latina han tenido las luchas por la igualdad de género y el respeto a la diversidad.

Son los movimientos de mujeres contra la explotación laboral y sus demandas sociales, desde una herencia de las luchas internacionalistas, los que han tenido un recorrido más largo en esta región, y con más memoria y fuerza en Argentina, Chile y México. Aunque todos los países han tenido sus expresiones, la cantidad de registros de memoria en prensa nos llevan a ubicar estas iniciativas en el marco de un contexto de tensión política (30). Mientras que los colectivos y movimientos de lesbianas, gais, transexuales, bisexuales, intersexuales y queer (LGTBIQ) se visibilizan en un ejercicio de la comunicación mucho más reciente y con la motivación de sucesos y acciones políticas en Norteamérica y Europa, es a finales de los años 1970 que se crean las condiciones para la visibilidad del movimiento homosexual, al mismo tiempo que se organizan los movimientos indígenas, de negros y de mujeres en algunos países de América Latina. El movimiento homosexual comenzó a plantear como problemas a considerar en la agenda política los valores de su vida cotidiana, el hacer público/privado, el autoafirmarse como sujetos homosexuales en la sociedad. Los movimientos más significativos después de 1968 surgirían en Nueva York y, en América del Sur, en Buenos Aires, como los describe Figari (31).

Las movilizaciones del movimiento feminista y LGTBIQ motivaron también la reciente reflexión de colectivos de hombres que sintieron la necesidad de resignificar sus roles de género y participar como sujetos activos en pro de la igualdad, bajo consignas en las que visibilizan las consecuencias del patriarcado para todos los géneros. Es así que, desde los años 1990 y en la última década se han organizado en redes y asociaciones que promueven narrativas y prácticas que transgreden la masculinidad hegemónica, como lo describen Gómez y Meneses (32).

Así mismo, la identidad que se construye para dar cuenta de las diferencias también marca relaciones de poder. En el caso de la identidad de género diversa, es la ciencia médica la que ha construido las narrativas bajo las cuales alguien subjetiviza su diversidad. Soley-Beltrán (33) a través de sus investigaciones nos hace ver la transexualidad, el transgénero y otras migraciones de género como prácticas y categorías médicas que han estado atravesadas por cuestiones de Bioética desde sus mismos inicios. Incorporar la distinción sexo/ género como parte de los protocolos de tratamiento y etiología de la denominada disforia de género fue considerada por este mismo sector como una acción inspirada por una ética humanista, pues su fin era aliviar el sufrimiento de los pacientes que declaraban sentir un doloroso desacuerdo entre su identidad - masculina o femenina- y su morfología física. Dice:

Desde sus inicios como categoría psicológica, la distinción sexo/género ha tenido un largo recorrido al ser adoptada por la segunda ola del movimiento feminista como categoría sociológica con el fin de articular la lucha en contra de la noción de la biología como destino 
y causa "natural" de la división del trabajo y roles sociales. (33, p33)

Entonces, cuando se le interpela a la Bioética por una posición al respecto, autores como Sevilla-González y Álvarez-Licona (34) plantean que no es bioético aceptar las normas que las mayorías establecen, bajo preguntas como: ¿dónde quedan los derechos de las minorías? ¿No tienen ellas derecho a existir, a ser tratadas en los mismos términos que cualquier ciudadano? Los derechos de los seres humanos no pueden establecerse basándose en una relación porcentual ni cuantitativa.

En oposición a esta perspectiva, también se encuentran enfoques, desde la Bioética, que hacen un llamado a mantener el orden social establecido y usan las ciencias médicas y la biología para reafirmar sus posturas. Así lo deja claro De los Ríos (28) cuando afirma que

es imperante atender el dualismo sexo-genérico desde una mirada Bioética compasiva que corrija pero abrace, que sea capaz de develar la verdad del ser humano a la luz de la empatía y del acompañamiento solidario, no en virtud del cuidado necesario, sino en virtud del reconocimiento de nuestra común condición humana vulnerable. (p132)

Se entiende que, de acuerdo con el tipo de diversidad sexual que se defienda, se admitirá o no un sustento biológico o un componente fijo e inamovible para la práctica de las conductas que de estos se puedan derivar.

Estos planteamientos nos hacen ver la compleja responsabilidad que tiene la Bioética en la promoción de unos principios y de un marco ético y pedagógico que permitan dar cuenta de una sociedad que hace rato transgredió las normas convencionales y que necesita de otros estatutos que reconozcan la dignidad de la vida en toda su diversidad. En sus análisis, Larrondo-Ureta (35) afirma cómo en este camino los activismos de género movilizan demandas. También muestra que es a partir de estas preguntas y este contexto histórico que se comprenden las luchas de género y la construcción de narrativas que posicionan sus acciones de resistencia a través de palabras e imágenes en sus prácticas comunicativas, las cuales, actualmente, con el uso de las tecnologías de la información y comunicación, se enriquecen en formatos multimediales, de colores, con fuerza estética y gráfica, pero, además, posicionan discursos disruptivos de la heteronormatividad como elemento común. Ello permite la construcción de otras subjetividades y la desnormalización de la violencia de género como el resultado de mayor impacto.

Las redes sociales se han configurado como espacios de comunidades en donde se pueden hacer conexiones entre personas que comparten intereses comunes. También, como lo manifiesta Castells (36), el ciberespacio es una herramienta importante de comunicación, organización y movilización social que puede incluso ser un instrumento de dominación. La capacidad comunicativa y de conexión entre sujetos que propone internet ha lanzado a las organizaciones sociales a incursionar en el ámbito de las comunicaciones digitales para visibilizar sus acciones, tener un mayor alcance de sus ideas y posicionar su agenda. El potencial de las redes sociales en internet para generar movilizaciones y acciones sociales está en la primavera árabe y pasa por los movimientos de indignación en España, el levantamiento en Egipto y el Occupy Wall Street, entre otros. Son acciones que se organizan en las redes sociales digitales y que se encuentran fuera del alcance de los gobiernos (37). Esto se puede entender como una retórica de la objetividad de internet según la cual estamos en manos de la sabiduría o de la estupidez de las masas.

Martel (38), en su estudio sobre internet, identifica que no se puede decir que exista una internet global, pues la idea y la experiencia de uso de internet depende del contexto económico, social y político en que esta se desarrolla. "A pesar de su imagen global uniforme, internet es diferente en todas partes" (p49). En este sentido, se comprende mejor lo que plantea Gómez-Cruz (39) sobre el sentido y el significado que cada uno le da a internet, desde tres dimensiones:

Pienso en él [el internet] como combinando tres cosas (...). Tiene dimensiones materiales, simbólicas y de experiencia. Es máquinas, cables, electricidad, programas, pantallas, conexiones y es modos de información y comunicación: correo electrónico, sitios web, chat rooms, MUD. Pero es también imágenes e ideas: el ciberespacio existe en el cine, en la ficción, 
en nuestras imaginaciones, tanto como en nuestros escritorios o en el espacio entre nuestras pantallas. Más aún, y este es un punto interesante, nosotros experimentamos el ciberespacio y todas sus manifestaciones mundanas y espectaculares al "mediar" lo material y lo simbólico. (39, p22)

Lo planteado por Martel y Bell se articula con la categoría analítica de cibercultura de Lévy (40) en el informe al Consejo de Europa, en el cual identifica la existencia de internet como un conjunto de dispositivos y de prácticas que evidencian las formas tradicionales de hacer del ser humano, a lo que se conoce como la sociedad del conocimiento. Estas formas de hacer son las mismas de la vida real llevadas a un escenario virtual en renovados formatos. Las estructuras y sistemas de organización social hacen el tránsito a un dispositivo de mediación, según Lévy, más abierto y democrático. Pero ese tránsito de lo real a lo virtual está determinado por el conocimiento, el uso y la apropiación de las tecnologías de información de cada una de las organizaciones estudiadas y de los contextos políticos en los que plantean sus luchas.

Las condiciones en que cada organización accede a las tecnologías de información y comunicación no son las mismas, dependen del territorio en que se mueven, de las políticas y las regulaciones que cada Estado implementa sobre el acceso y uso de internet. También, el conocimiento y experiencia de uso de internet determina la forma en que se presentan los temas, las agendas y los contenidos en redes sociales y sus páginas web. A estos componentes los denominamos análisis situacional, que se desarrolla en el marco de un enfoque metodológico guiado por la etnografía.

La etnografía fue útil para observar y describir estos entornos del mundo real. En el ciberespacio, la etnografía se presenta como un enfoque que nos permite comprender las prácticas y las relaciones en el contexto virtual, pero vinculadas a las prácticas y a las relaciones del contexto real. Esto es a lo que se denomina el análisis multisituado (41). Nuestro análisis multisituado sigue el planteamiento de Daniel Bell (42) respecto a los elementos del ciberespacio y la forma en que interpretamos estos entornos de interacción desde lo material, lo simbólico y la experiencia. La etnografía desarrollada en los entornos virtuales nos da una visión de estas tres dimensiones al poderlas ubicar en una organización social y en unas acciones colectivas puntuales en las redes sociales.

\section{Resultados de la observación}

Las movilizaciones ciudadanas acontecidas en los últimos años en diferentes partes del mundo han encontrado en internet $y$, especialmente, en redes como Facebook y Twitter un instrumento y un espacio no solo para expandir los objetivos de sus acciones, sino también para convertirlo en el principal vehículo a través del cual ejercen su proceso de comunicación y organización. Sucedió en la primavera árabe, durante la cual

[e]l papel de la Red, su eficacia y la intensidad de las comunicaciones ha sido diferente en los distintos momentos de los conflictos. Internet y las redes sociales fueron útiles para superar el aislamiento de la sociedad árabe, para hacer visibles las revoluciones y para conseguir apoyos relevantes del exterior. (43, p152)

Ocurrió también con los indignados en España, donde, como indicaba Robles et al.,

(...) los dispositivos de comunicación digital, en especial internet, son un espacio central de intervención política que permitió al movimiento $15-\mathrm{M}$, además de generar y difundir un discurso (marco), construirse como actor político más allá de los marcos convencionales de sentido que son articulados y re-producidos por los medios de comunicación tradicionales. $(44$, p53)

Si bien las consecuencias derivadas de estos eventos no son única y exclusivamente atribuibles a las acciones realizadas a través de las redes, como anotan Feixa, et al., (45), en el caso de España

[e]l 15-M se ha caracterizado por la eclosión de las tecnologías 2.0, por la experimentación y búsqueda de nuevos usos. Sin embargo, este rasgo no ha supuesto la eliminación de otras herramientas y actitudes analógicas. No se ha tratado de una dicotomía, sino de reforzar, complementar y retroalimentar las distintas dinámicas y herramientas de comunicación existentes. $(45, \mathrm{p} 118)$

Dichas manifestaciones llevan a pensar que el uso de redes juega un papel clave como apoyo comunicativo y de visibilidad de las luchas dadas 
en la coyuntura política y social en estos lugares, y que el fácil acceso a estas origina singulares formas de participación en lo político y en lo social, que producen nuevos escenarios ligados a lo público. De esto no es ajeno América Latina, donde, en los últimos años, las tensiones sociales reclaman escenarios como el que posibilita internet y que invita a preguntarnos, como inicialmente se plantea en esta investigación, si estas tecnologías son instrumentos para la emancipación o si más bien son otro elemento más de marginación y subordinación de los movimientos sociales con enfoque de género.

Como lo afirman Sierra-Caballero y Gravante (46), América Latina está redefiniendo la manera como se apropia de las tecnologías. La comunicación comunitaria ha desarrollado usos en los que se fortalece lo local y la identidad a través de canales de difusión que permiten audiencias globales, a las que antes era imposible acceder. Según el autor, esto va en línea con la tradición latinoamericana en comunicación ciudadana y participativa, que ha dado lugar a múltiples experiencias de articulación con medios digitales y analógicos en sus protestas (46).

El proceso hacia la expansión de la participación de organizaciones en las nuevas tecnologías no ha sido ajeno a las distintas agrupaciones y colectivos que nacieron antes de la popularización de internet y que han realizado el tránsito hacia esta, encausando sus objetivos hacia el uso del ciberespacio como medio de sus prácticas y luchas. Es el caso de las organizaciones observadas en esta investigación, en la cual se busca identificar los usos y apropiaciones de las tecnologías que estas tienen.

La investigación se inició indagando acerca de la agenda de las publicaciones de las organizaciones observadas, compuestas principalmente por acontecimientos mediáticos y políticos que marcaban el momento de la publicación. Un ejemplo es el caso del movimiento surgido a partir del proyecto de ley en argentina sobre la despenalización del aborto. Este caso creó picos tanto en publicaciones como en retuits, en los momentos en que el proyecto cursaba por el Congreso argentino, como bien lo sistematiza el trabajo realizado por Rubin y Zanotti (47). Sucedió de igual manera con la llegada al poder en Brasil de Jair Bolsonaro, la conmemoración de fechas llamativas como el 8 de marzo, la discusión de políticas públicas a nivel local y la violencia de género cuando algún crimen o manifestación social cobraba figuración mediática. Así lo registra Campos (48), describiendo la construcción del concepto de ideología de género a través de discursos de odio y estigmatización, tanto hacia los activismos feministas como hacia las comunidades en condiciones de diversidad sexual.

En los siguientes gráficos se visibilizan las temáticas más recurrentes de publicación en las redes sociales observadas y los tipos de contenido como tendencia.

\section{Temas}

Gráfico 1. Temas en Twitter y Facebook

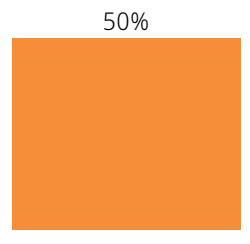

PEDAGOGÍA

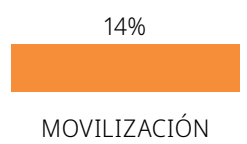

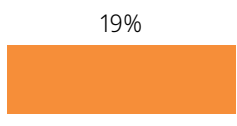

EMPODERAMIENTO

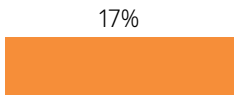

DENUNCIA

Elaboración propia. 
La información del Gráfico 1 se obtuvo a través de los datos arrojados por el instrumento de observación aplicado a las cuentas de Twitter y de Facebook de las organizaciones previamente seleccionadas en la muestra del periodo junio 2018 a junio 2019. Se examina el contenido acerca de cuál es la temática de cada publicación observada y como resultado se obtienen diferentes tendencias, que fueron agrupadas en cuatro categorías: pedagógica, movilización, empoderamiento y denuncia.

Tanto en Twitter como en Facebook, cerca de la mitad de los datos arrojados mostraron una orientación hacia la categoría pedagógica, por encima de empoderamiento, denuncia y movilización. Paralelamente a esto, se indagó acerca de cuál era el propósito de cada publicación, dando como resultado que informar, seguido de compartir y publicitar son los propósitos más frecuentes dentro de las publicaciones de las organizaciones observadas.

Se observa que el contenido compartido no se diferencia en cuanto a temática y propósito en estas dos plataformas y que tienden a ser usados de manera similar. A partir de allí podemos advertir que el uso de Facebook y Twitter se da principalmente con el fin de transmitir contenido de tipo informativo, con fines pedagógicos, de difusión de publicidad o simplemente de compartir información.

Los datos resultantes del instrumento aplicado encaminan a indicar que el uso dado a las Tic en lo referido a Twitter y Facebook por las organizaciones observadas se centra en transmitir contenido

Gráfico 2. Tipo de contenido en Twitter y en Facebook de tipo informativo, con fines pedagógicos, de concientización y de sensibilización, de difusión de publicidad o simplemente de compartir información. Esto nos lleva a asumir que estas redes son utilizadas principalmente como mecanismos de difusión, más que como espacios para generar instrumentos de emancipación, no sin concluir que no tengan influencia. Las \#etiquetas son muestra de esto, pero terminan siendo tendencias emergentes no necesariamente originadas desde organizaciones, sino, muchas veces, desde la convergencia de fuerzas que promocionan estas categorías un tanto efímeras al compás de la relevancia o de la atracción de eventos mediáticos. Algo a lo que PPecourt-Gracia y Villar-Aguilés (49) llamaron públicos indexados, que no son más que comunidades organizadas en torno a temas de interés común.

\section{Tipo de contenido}

Con el instrumento aplicado, se indagó acerca del tipo de contenido de la publicación, para el cual se habían dispuesto previamente las siguientes alternativas: video, texto, imagen, audio, enlace $u$ otro, con la posibilidad de seleccionar más de uno. Esto generó quince alternativas de contenido de publicación en las cuentas observadas de Twitter y siete en las de Facebook, siendo texto-imagen la de mayor frecuencia, seguida de imagen, texto y texto-enlace en ambas plataformas. Los datos se encuentran en la Gráfica 2. 
Al realizar un cruce de información entre los datos de tipo de contenido con la temática de mayor frecuencia de la publicación (pedagógico), se arrojó como resultado que también texto-imagen, imagen y texto son las publicaciones que se dan con mayor frecuencia, como se observa en la Gráfica 3.

Gráfico 3. Tipo de contenido y tema pedagógico

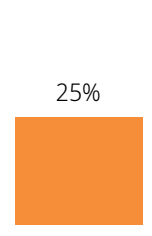

IMAGEN

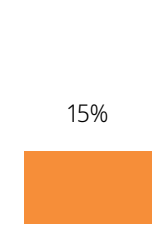

TEXTO

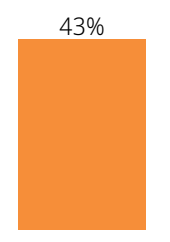

TEXTO

IMAGEN

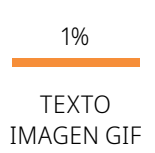

Elaboración propia.
Se observa que la mayoría de las publicaciones de las organizaciones en Twitter y Facebook están acompañadas de imágenes complementadas con texto o enlaces que denotan que el carácter pedagógico e informativo es visto como la principal temática y se nutre de dispositivos visuales en cuanto a las prácticas de uso de las distintas organizaciones observadas. Llama la atención la prevalencia de lo visual en Twitter, dando a entender que el enfoque de la publicación se dirige cada vez más hacia una ecología de tipo multimedia, más atrayente, acogedora al seguidor y con mayor impacto, que al flujo de textos limitado por cierto número de caracteres. Cabe resaltar que, a excepción de las imágenes, las publicaciones carecen de otros complementos multimedia como video o audio. Estos se dejan para otro tipo de redes, como, posiblemente, Facebook o YouTube.

\section{Uso de la etiqueta y tema}

A pesar de que más de la mitad de las publicaciones realizadas por las organizaciones carecen de etiqueta, las que sí la usan pertenecen a publicaciones con temáticas enfocadas en la pedagogía. Muchas de estas temáticas son alentadas y copiadas como tendencia de eventos de gran revuelo público circunstancial con el propósito de informar, concientizar y movilizar; no se ambientan en un espacio físico, sino en espacios virtuales categorizados en tendencias en busca de la viralización. El uso de las etiquetas se presenta en la Gráfica 4.

Gráfico 4. Uso de la etiqueta y tema en Twitter

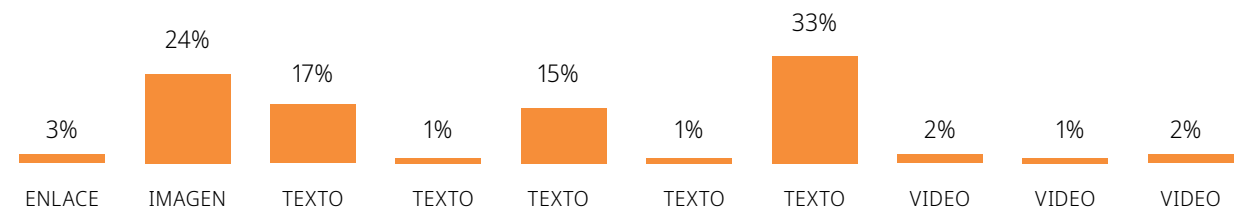


Estas características comunicativas son tanto una narrativa como una acción colectiva en la cual podemos observar una división en la defensa del género, posicionando un deber ser desde lo masculino, desde lo femenino y desde la diversidad, pero, también, una causa común de la libre autodeterminación. En el caso de las organizaciones, la visibilización en las redes hace parte de una comunicación visual para posicionar sus ideas, acciones y prácticas. Estas se manifiestan de diferentes formas y con diversas estéticas que comunican una alianza cercana con las luchas feministas, incluso en sus iconos y temáticas. En otras oportunidades, plantean la construcción de nuevas subjetividades masculinas con iconos propios.

La etiqueta acompañada de imágenes de denuncia se ha vuelto bastante popular en las redes sociales, teniendo en cuenta que, como herramienta comunicativa, las etiquetas permiten presentar de manera pública y organizada en una línea del tiempo todos los contenidos que se clasifiquen con la misma etiqueta. Así se facilita no solo su ubicación, sino el intercambio de información o de contenidos entre distintos usuarios, sobre determinados temas o acontecimientos. Estas características les otorgan mayor visibilidad a los temas.

Las narrativas que representan movilización se centran en dar cuenta de acciones que trascienden el mundo virtual y la distribución de información y contenidos hacia la toma del espacio público. Se dan acciones digitales previas de convocatoria y la movilización efectiva de los cuerpos que se toman las calles y que alzan pancartas que posicionan narrativas afines a sus intereses. Esto expresa una triple movilización, en la que el ciberespacio es escenario de invitación, motivación y movilización de información. El espacio público es un lugar de ocupación de debate físico y los registros de estas acciones son llevados de nuevo al ciberespacio, para amplificar la acción, para preparar otras y como existencia postfacto de qué ocurrió y cómo ocurrió.

Siguiendo a Núñez-Puente et al. (50), en las manifestaciones de activismo digital se observa al ciberfeminismo como una práctica en la que se construyen formas comunicativas en las cuales el acontecimiento hace parte de la potencia social que vincula el mundo digital con el mundo físico y desde esa vinculación se ejercen las ciudadanías en los contextos políticos contemporáneos. Es evidente que, en esta relación entre género, ciberactivismo y Bioética, son más las prácticas de resistencia y los estudios desde los movimientos feministas, que sobre otros tipos de reivindicaciones, como las de las masculinidades o la diversidad sexual, ya que allí convergen temas en disputa permanente, como lo son el aborto y el feminicidio.

\section{Conclusiones}

Sin duda, este texto propone una intersección compleja entre ciberactivismos, género y Bioética, en la cual la comunicación mediada por las redes sociales permite evidenciar los retos de diálogo interdisciplinar desde lo social. Esto implica abordar la construcción de subjetividades que demandan la reconfiguración de límites y acuerdos éticos frente a la vida.

Las agendas, las prácticas, la movilización y la participación de las organizaciones estudiadas se asumen tanto desde la ocupación de los espacios digitales como de los espacios físicos y están marcadas, en gran medida, por la producción de contenidos que muestren acontecimientos propios de los colectivos en función de manifestar y e informar su acontecer, de promocionar eventos locales y de sumarse a alternativas de expresión como tendencias a través de las etiquetas y de las "tuiteratones". Estas acciones marcan la atención en las redes sociales y pueden representar, para la organización, un tipo de acción solidaria y vinculante con su causa, que moviliza tantas narrativas como acciones políticas de impacto en lo público y lo privado.

Se observa cómo mientras los movimientos feministas tienen en sus luchas el tránsito con voz y poder de lo privado a lo público como un lugar de acción y decisión, para los movimientos de hombres, como nuevas masculinidades, se busca, por el contrario, hacer tránsito y presencia y validarse desde el espacio público a los espacios privados. En esto último, lo pedagógico trata de visibilizar las condiciones emergentes de empoderamiento en paternidades o actividades sensibles (bordar, cocinar), la movilización hacia lo privado, el empoderamiento entendido como asumir roles no 
convencionales y muy pocos de denuncia. En este caso, no son los cuerpos los que se sienten vulnerados, sino los roles que han sido socialmente normalizados.

Como elementos comunes en todos los colectivos, se denuncia al patriarcado y se presentan a los hombres como generadores de violencia y a las mujeres y población LGBTIQ como receptoras de violencia. Así mismo, las mujeres se muestran como sujetos denunciantes y lo masculino, como sujeto denunciado.

Llama la atención cómo la imagen cobra protagonismo como elemento de divulgación y comunicación. Las imágenes, a la vez, reproducen muchas veces miradas biologicistas (como la de los cromosomas XY) $y$, teniendo en cuenta que estos movimientos abogan por un enfoque de género desde lo cultural y no desde lo heteronormativo, generan una contradicción entre el símbolo que se utiliza y el discurso que se pretende presentar.

En el caso de los colectivos relacionados con las identidades diversas, las demandas se centran en contra de la discriminación, de la violencia y por el reconocimiento de derechos civiles, como el matrimonio y la adopción igualitaria. Para los colectivos que se movilizan en torno a las nuevas masculinidades, el accionar es más reciente y afín con las demandas del movimiento feminista que reclama la eliminación de los estereotipos de género, la redistribución de las tareas domésticas y de cuidado. En general, se plantea un proceso disruptivo frente al patriarcado y la heteronormatividad, como discursos y prácticas hegemónicas de asumirse y representarse como hombres.

En atención al tránsito de una perspectiva de la Bioética enfocada en lo clínico hacia una Bioética enfocada en lo social, es expresa la necesidad que desde esta última se puedan afrontar las profundas manifestaciones de movimientos nacidos y perpetuados en el ciberespacio, en contra de cualquier forma de discriminación y de defensa por el pleno goce de libertades fundamentales relacionados con el género. Allí es necesario abrir nuevos frentes de investigación y profundizar los existentes en pro de abordar temáticas relacionadas con nuevas formas de exclusión social y aumento de brechas frente al uso tecnologías y las implicaciones Bioéticas que esto genere.

En el contexto de perspectivas distópicas y utópicas acerca de lo que las tecnologías de la información y la comunicación pueden hacer en la sociedad, se perciben múltiples posibilidades de usos y apropiaciones de las Tic. Así, hablar de lógicas que permiten crear, compartir y cocrear desde órdenes diversos y por fuera de la gubernamentalidad puede llegar a ser promisorio en la construcción de libertad, a través del uso de internet, para conducirnos a un mundo más allá de las polaridades, incluso de género.

\section{Referencias}

1. Cuevas-Silva JM, Mendieta-Izquierdo G, Ramírez-Rodríguez JC. Género y Bioética: entre discursos e ideologías. Rev Latinoam Bioét [Internet]. 2018 Ag 17;18(35-2):6-10. Disponible en: https://doi. org/10.18359/rlbi.3213

2. Un. Cepal. Entre mitos y realidades. TiC, políticas públicas y desarrollo productivo en América Latina. Santiago de Chile: Naciones Unidas; 2013.

3. Núñez-Puente $S$, Fernández-Romero D, Peña-Jiménez P. Ciberactivismo contra la violencia de género: fetichismo tecnológico e interactividad. Feminismo/s [Internet]. 2016;(27):177-195. Disponible en: https://doi. org/10.14198/fem.2016.27.10

4. Butler J. El género en disputa: el feminismo y la subversión de la identidad. Barcelona: Paidós; 2007.

5. Valcarcel AS, Fernández EG, Martínez AC. Acción colectiva ciberactivista de "Las periodistas paramos" para la huelga feminista del $8 \mathrm{M}$ en España. Comun Soc [Internet]. 2019 Jun 5;(16):1-24. Disponible en: https://doi.org/10.32870/cys.v2019i0.7287

6. Collado J. Biomímesis: un abordaje transdisciplinar a la educación para la ciudadanía mundial. ridas Rev Iberoam Aprendiz-Serv [Internet]. 2017 My 23;(3):3554. Disponible en: DOI10.1344/RIDAS2017.3.4

7. García-Gutiérrez J, Gil-Cantero F, Reyero-García D. El sujeto ético en los estudios universitarios de educación: humanismo, posthumanismo y democracia. Bordón Rev Pedagog [Internet]. 2017 Sept 20;69(4):1933. Disponible en: https://doi.org/10.13042/Bordon.2017.690402

8. Velayos-Castelo C. Bioética, ecología y género. Rev Filos Univ Costa Rica [Internet]. 2013 Ag 26;50(127-128). 
Disponible en: https://revistas.ucr.ac.cr/index.php/filosofia/article/view/11677

9. Urrea-Mora FC. El cuerpo de las mujeres gestantes: un diálogo entre la Bioética y el género. Rev Colomb Bioét [Internet]. 2015 Nov 11;7(1):97-110. Disponible en: https://doi.org/10.18270/rcb.v7i1.804

10. Reig-Hernández D. TIC, TAC, TEP: internet como escuela de vida. Cuad Pedagog [Internet]. 2016;(473):2427. Disponible en: http://hdl.handle.net/11162/131746

11. Manzano-Zambruno L. ¿Es el \#MeToo un movimiento? Una revisión sobre el concepto "movimiento social" y su relación con las redes sociales. En: Paredes-Otero $\mathrm{G}$, editor. Investigar las redes sociales Un acercamiento interdisciplinar. Sevilla: Egregius; 2019. p. 15-34.

12. Arriazu-Muñoz R. ¿Nuevos medios o nuevas formas de indagación?: Una propuesta metodológica para la investigación social on-line a través del foro de discusión. Forum Qual Sozialf/Forum Qual Soc Res [Internet]. 2007;8(3). Disponible en: https://www.qualitative-research.net/index.php/fqs/article/view/275/606

13. Turpo Gebera OWT. La netnografía: un método de investigación en Internet. Educ [Internet]. 2008;(42):8193. Disponible en: https://doi.org/10.5565/rev/ educar.134

14. Boellstorff T, Nardi B, Pearce C, Taylor TL. Ethnography and Virtual Worlds: A Handbook of Method. Princeton: Princeton University Press; 2012.

15. Morse JM, editor. Asuntos críticos en los métodos de investigación cualitativa. Medellín: Universidad de Antioquia; 2003.

16. Meneses-Cabrera T, Cardozo-Cardona JJ. La Etnografía: una posibilidad metodológica para la investigación en cibercultura. Encuentros [Internet]. 2014;12(2):93-103. Disponible en: https://www.redalyc. org/pdf/4766/476655660007.pdf

17. Ruiz-Méndez M del R, Aguirre-Aguilar G. Etnografía virtual, un acercamiento al método y a sus aplicaciones. Estud Cult Contemp [Internet]. 2015;21(41):6796. Disponible en: https://www.redalyc.org/ pdf/316/31639397004.pdf

18. Aguilar-Forero N. Ciberactivismo y olas de agitación comunicativa. Consideraciones etnográficas. Íconos Rev Cienc Soc [Internet]. 2017 Sept 4;(59):123-148. Disponible en: https://doi.org/10.17141/ iconos.59.2017.2595

19. Bonilla-Castro E, Rodríguez P. Más allá del dilema de los métodos. La investigación en ciencias sociales. Bogotá: Editorial Norma; 2005.
20. LANIC. Latin American Network Information Center [Internet]. Texas: Universidad de Texas; 2015 [visitada en 2019 Abr 1]. Disponible en:_http://lanic.utexas.edu/ la/region/women/indexesp.html

21. Albert M. Las condiciones personales del razonamiento bioético. Cuad Bioét [Internet]. 2019;30(99):211-215. Disponible en: DoI: 10.30444/CB.34

22. Bárcenas-Barajas K, Preza Carreño N. Desafíos de la etnografía digital en el trabajo de campo onlife. Virtualis [Internet]. 2019 Sept 5;10(18):134-151. Disponible en: https://www.revistavirtualis.mx/index.php/ virtualis/article/view/287

23. Moncayo MF. La etnografía virtual como método de investigación en el diagnóstico de la comunicación corporativa. estrategas Investig Comun [Internet]. 2017 Mzo 2;3. Disponible en: http://marketing.udla. edu.ec/ojs/index.php/estrategas/article/view/104

24. Trinidad-Requena A, Carrero-Planes V, Soriano-Miras RM. Teoría fundamentada "Grounded theory": la construcción de la teoría a través del análisis interpretacional Madrid: Centro de Investigaciones Sociológicas; 2006.

25. Corbin J, Strauss A. Basics of Qualitative Research ( $3^{\text {rd }}$ ed.): Techniques and Procedures for Developing Grounded Theory. 3. ${ }^{\mathrm{a}}$ ed. Thousand Oaks: sage Publications, Inc.; 2008.

26. Wolcott HF. Mejorar la escritura de la investigación cualitativa. Invest Educ Enferm [Internet]. 2004 Sept; 22(2):150-162. Disponible en: https://dialnet.unirioja. es/servlet/articulo?codigo $=1321689$

27. Pérez JAP. Redes sociales virtuales y la Bioética. El Ágo USB [Internet]. 2011 En 18;11(1):175-204. Disponible en: https://revistas.usb.edu.co/index.php/Agora/article/view/381

28. De los Ríos ME. Bioética y género: análisis desde la vulnerabilidad humana. Rev Med Ética [Internet]. 2019 Nov 8;30(4):1317-1336. Disponible en: https://doi.org/10.36105/mye.2019v30n4.04

29. Estrada-Montoya JH. Las violencias de género como problema de salud pública: una lectura en clave Bioética. Rev Colomb Bioét [Internet]. 2015 Nov 19;6(1):3761. Disponible en: https://doi.org/10.18270/rcb. v6i1.1266

30. Curiel-Pichardo RYO. Descolonizando el feminismo: una perspectiva desde América Latina y el Caribe. Mov Muj Fem [Internet]. 2009;(294). Disponible en: https://repositorio.unal.edu.co/handle/unal/75231 
31. Figari C. El movimiento LGBT en América Latina: institucionalizaciones oblicuas. En: Massetti A, Villanueva E, Gómez M, compiladores. Movilizaciones, protestas e identidades colectivas en la Argentina del bicentenario. Buenos Aires: Nueva Trilce; 2010. p. 225-240.

32. Gómez RA, Meneses T. Género y emergencias sociales. Vinculando las masculinidades a las políticas públicas desde la Bioética social. Rev Latinoam Bioét [Internet]. 2018 Jun 21;18(35-2):62-79. Disponible en: https://doi.org/10.18359/rlbi.3388

33. Soley-Beltran P. Transexualidad y Transgénero: una perspectiva Bioética. Rev Bioét Der [Internet]. 2014 En 15;(30):21-39. Disponible en: https://doi.org/10.4321/ S1886-58872014000100003

34. Sevilla-González MdlL, Álvarez-Licona NE. Normalización del discurso homofóbico: aspectos bioéticos. Acta Bioeth [Internet]. 2006;12(2):211-217. Disponible en:https://doi.org/10.4067/S1726-569X2006000200010

35. Larrondo-Ureta A. La Red al servicio de las mujeres. Aproximación a la relación mujer y medios de comunicación en Internet. Est Mens Period [Internet]. 2005 En 1;11:375-392. Disponible en: https://revistas.ucm. es/index.php/ESMP/article/view/ESMP0505110375A

36. Castells M. La Galaxia Internet. Reflexiones sobre Internet, empresa y sociedad. Madrid: Editoral Areté; 2001.

37. Castells M. Redes de indignación y de esperanza. Movimientos sociales en la era de internet. Madrid: Alianza Editorial; 2012.

38. Martel F. Smart Internet(s): la investigación. Madrid: Taurus; 2014.

39. Gómez-Cruz E. Las metáforas de Internet. Barcelona: Editorial Uoc; 2007.

40. Lévy P. Cibercultura. La cultura de la sociedad digital. Barcelona: Rubí; México: Anthropos, Universidad Autónoma Metropolitana; 2007.

41. Aguilar-Forero N. Ciberactivismo y olas de agitación comunicativa. Consideraciones etnográficas. Ícon Rev Cienc Soc [Internet]. 2017 Sept 4;21(59):123-148. Disponible en: https://doi.org/10.17141/iconos.59.2017.2595

42. Letraslibres.com [Internet]. Daniel Bell; 2000 [visitada en 2019 Abr 1]. Disponible en: https://www.letraslibres.com/mexico/internet-y-la-nueva-tecnologia

43. Soengas X. El papel de Internet y de las redes sociales en las revueltas árabes: una alternativa a la censura de la prensa oficial. Comun [Internet]. 2013;21(41):147-155. Disponible en: https://doi.org/10.3916/C41-2013-14
44. Robles JM, Díez R, Castromil AR, Rodríguez A, Cruz M. El movimiento 15-M en los medios y en las redes. Un análisis de sus estrategias comunicativas. Emp Rev Metodol Cienc Soc [Internet]. 2015 Sept 21;(32):3762. Disponible en: https://doi.org/10.5944/empiria.32.2015.15308

45. Feixa C, Fernández-Planells A, Figueras-Maz M. Generación Hashtag. Los movimientos juveniles en la era de la web social. Rev Latinoam Cien Soc [Internet]. 2016 Mzo 4;14(1):107-120. Disponible en: https://doi.org/10.11600/1692715x.1416301115

46. Sierra-Caballero F, Gravante T. Ciudadanía digital y acción colectiva en América Latina. Crítica de la mediación y apropiación social por los nuevos movimientos sociales. Tram Com [Internet]. 2016;20(1), 163-175. Disponible en: https://doi.org/10.35305/lt.v20i1.568

47. Rubin P, Zanotti A. Escribir la Historia: activismo en Wikipedia y el debate por la despenalización del aborto en Argentina. Commons Rev Com Ciud Digit [Internet]. 2019 Dic 18;8(2):122-158. Disponible en: https://doi.org/10.25267/COMMONS.2019.v8.i2.04

48. Campos A. "Ideología de género". Breve historia de un oscuro concepto. Bordes [Internet]. $2020 \mathrm{Mzo}$ 4;(15):231-240. Disponible en: https://publicaciones. unpaz.edu.ar/OJS/index.php/bordes/article/view/623

49. Pecourt-Gracia J, Villar-Aguilés A. Orígenes de las movilizaciones \#primaveravalenciana. Un análisis de los actores sociales más influyentes en Twitter. Athenea Digit Rev Pensam Investig Soc [Internet]. 2018 Jun 6;18(2). Disponible en: https://doi.org/10.5565/rev/ athenea. 1857

50. Núñez Puente S, Vázquez Cupeiro S, Fernández Romero D. Ciberfeminismo contra la violencia de género: análisis del activismo online-offline y de la representación discursiva de la víctima. Est Mens Period [Internet]. 2016;22(2):861-877. Disponible en: https://doi.org/10.5209/ESMP.54240 